\title{
NOTARUM EXPLICATIO.
}

\author{
Bg. = Böcking. \\ Bl. = Bluntschlj. \\ C. $=$ Codex Vaticanus. (Cf. pracf. not. ${ }^{* *}$ ) \\ Cui. = Cuiacius. \\ H. = Hugo. \\ Hollw. = Bethmann-Hollweg. \\ Marez. = Marezoll. \\ Schill. = Frid. Ad. Schilling. \\ Schult. $=$ Schulting. \\ Cetera signa per se satis nota sunt
}

